\title{
PROCESSO DE INTERNACIONALIZAÇÃO DE MICRO E PEQUENAS EMPRESAS: UM ESTUDO DE CASO DE DUAS MPES DO SETOR DE ARTEFATOS EM AÇO INOX DE MINAS GERAIS
}

\author{
Rodrigo Alberto Peixoto Rodrigues de Souza ${ }^{1}$
}

RESUMO: Este trabalho analisa o processo de internacionalização de duas empresas do setor de artefatos em aço inox localizadas na região do Vale do Aço em Minas Gerais. A estratégia de pesquisa contatou as duas MPEs e solicitou a elas que respondessem a uma entrevista semiestruturada, investigando como se deu seu processo de internacionalização. O estudo mostrou que o apoio governamental para que MPEs se internacionalizem não é suficiente, devendo, portanto, a MPE desenvolver uma cultura exportadora, quebrar alguns paradigmas e se desenvolver efetivamente, até que consiga se internacionalizar. $\mathrm{O}$ planejamento de se internacionalizar deve partir da própria empresa e a mudança de cultura é o fator fundamental para que os passos seguidos por esta empresa a auxiliem no processo de internacionalização. Apesar dos mais variados modelos de internacionalização, foi possível identificar que aquela empresa que realmente desenvolveu uma cultura exportadora e definitivamente se internacionalizou, buscou a aplicação do modelo da Universidade de Uppsala, na Suécia.

Palavras-chave: Internacionalização. MPEs. Modelo da Universidade de Uppsala.

\section{INTRODUÇÃO}

Este estudo teve o objetivo geral de analisar o processo de internacionalização, as estratégias implantadas e os resultados alcançados, na visão dos dirigentes de duas MPEs produtoras de utensílios em aço inox, localizadas na região do Vale do Aço no Estado de Minas Gerais. Para isto, buscou-se a) caracterizar o processo de internacionalização utilizado pelas duas MPEs; b) analisar os procedimentos realizados pelas duas MPEs, em

\footnotetext{
${ }^{1}$ Professor dos Cursos de Administração de Empresas, Tecnólogo em Marketing, Tecnólogo em Gestão Hospitalar, Tecnólogo em Processos Gerenciais pela Faculdade Arnaldo Janssen em Belo Horizonte/MG https://orcid.org/oooo-oooı-5844-1931 Bacharel em Administração com Habilitação em Comércio Exterior Centro Universitário UMA. Pós-graduado em Marketing Estratégico pela Universidade Cândido Mendes UCAM Pós graduado em Gerenciamento de Projetos pela Faculdade Batista de Minas Gerais. Pós graduando em MBA em Gestão do Agronegócio pela Universidade de São Paulo - USP Mestre em Administração Estratégica pela FEAD. Mestre em Administração Estratégica pela Faculdade FEAD (2007). Especialista em Marketing pela UCAM e em Gestão de Projetos pela Faculdade Batista. Bacharel em Administração em Comércio Exterior pela UNA. Professor da Faculdade Arnaldo Janssen. E-mail: rodrigo.peixoto@gmail.com
} 
relação à gestão, envolvimento e interesse; e c) levantar os resultados alcançados com o processo de internacionalização dessas duas empresas.

A importância da condução do estudo centrou-se no fato de o contexto econômico, a partir do final do século XX, apontar para uma crescente globalização da economia, de forma que a empresa que melhor se adaptar a essa inevitável realidade se destacará no mercado internacional, confrontando-se, de igual para igual, com outras empresas localizadas nos mais diversos pontos geográficos do planeta. Govindarajan e Gupta (2001, p.138) afirmam que "liberalização, ascensão dos países em desenvolvimento, mudanças tecnológicas e queda das barreiras comerciais estão mudando profundamente o ambiente econômico. As empresas têm uma escolha simples, porém crucial: subir a bordo ou ficar para trás".

O processo de internacionalização constitui decisão importante, voltada ao crescimento das empresas, dos profissionais, dos recursos e das estratégias, envolvendo toda a organização (KUAZAQUI, 1999). No século XXI é premente romper com processos tradicionais, para enfrentar a disputa acirrada do comércio, não só local, mas também, e, principalmente, internacional. Para isto, conhecimento e investimento são essenciais, demandando tempo e dinheiro para implantação dessa nova realidade em que se faz urgente o processo de internacionalização das MPEs brasileiras.

Uma pesquisa elaborada em 1999, pela Associação Brasileira dos Exportadores ( $A B E)$ e pelo Serviço Brasileiro de Apoio às Micro e Pequenas Empresas (SEBRAE), apud Dias (2002), levantou junto às MPEs os principais obstáculos para elas conseguirem atuar no mercado internacional. Os resultados apontaram: a) obtenção conhecimento inicial adequado sobre exportações $(72 \%)$; b) identificação de produtos viáveis de venda no exterior (61\%); c) entendimento dos protocolos de negócios em outros países (57\%); e d) seleção de mercados-alvo adequados com base em informações disponíveis (57\%).

De posse dos resultados, Dias (2002) concluiu que há possibilidade de inserção de novas empresas na atividade exportadora. Todavia os desafios que se apresentam para o governo, setor privado, instituições financeiras e demais órgãos intervenientes no comércio exterior brasileiro, apontaram crescente necessidade de divulgar os mais diversos mecanismos de apoio existentes no país, pois, aos micro e pequenos empresários, falta conhecimento necessário para tal internacionalização. De acordo com Vieira (2004), o 
mercado passa a interagir cada vez mais com ferramentas como o conhecimento e a tecnologia, permitindo que as empresas possam alcançar altos padrões de concorrência e competitividade, o que justifica estudar duas MPEs de um mesmo segmento, localizadas em um mesmo ponto geográfico.

\section{REFERENCIAL TEÓRICO}

Neste referencial teórico são relevantes os modelos de internacionalização, características e classificação das MPEs brasileiras.

\section{MODELOS DE INTERNACIONALIZAÇÃO}

Já se criaram alguns modelos de internacionalização, enfocando-se neste estudo o modelo da Escola Nórdica de Negócios Internacionais, da Universidade de Uppsala, na Dinamarca, desenvolvido entre 1960 e 1970, e apresentado em 1977. O modelo trata de uma linha que analisa o comportamento organizacional considerado resultado de processos cumulativos de aprendizagem e não um evento isolado. Para Hilal e Hemais (2003, p. III), "um dos pressupostos subjacentes da escola é que a internacionalização da firma, por meio de exportações ou investimentos diretos, é uma consequência do seu crescimento".

Exportação é um dos caminhos para uma empresa se internacionalizar; porém, o simples fato de exportar não indica internacionalização, nem aquisição de conhecimentos suficientes para a MPE manter relação comercial internacional duradoura. Além desse modelo, o Uppsala, existem outros modelos teóricos de internacionalização subdivididos em modelos comportamentais e modelos econômicos, conforme descrito no Quadro I, a saber:

Quadro I

Modelos de internacionalização

\begin{tabular}{|c|c|c|}
\hline$\frac{0}{\frac{0}{0}}$ & Teoria & Definição \\
\hline \multirow{2}{*}{ 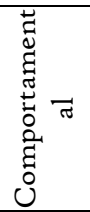 } & Uppsala I977/1990 & $\begin{array}{l}\text { Falta de conhecimento é obstáculo, conhecimento adquirido } \\
\text { por experiência é mais importante, a empresa internacionaliza- } \\
\text { se, investindo recursos de forma gradual. }\end{array}$ \\
\hline & $\begin{array}{c}\text { Teoria das Redes } \\
1988 / 1997 / 2000 / 2002 / 2003\end{array}$ & $\begin{array}{l}\text { Há a abertura de uma subsidiária em um determinado país, } \\
\text { que inicia o repasse de informações para a matriz. }\end{array}$ \\
\hline f: & $\begin{array}{c}\text { Custo de Transação } \\
\text { 1935/1971/1975 }\end{array}$ & $\begin{array}{l}\text { Quanto maior o custo na busca de informação, menos } \\
\text { problemas decorrentes de fechamento de contrato. }\end{array}$ \\
\hline
\end{tabular}




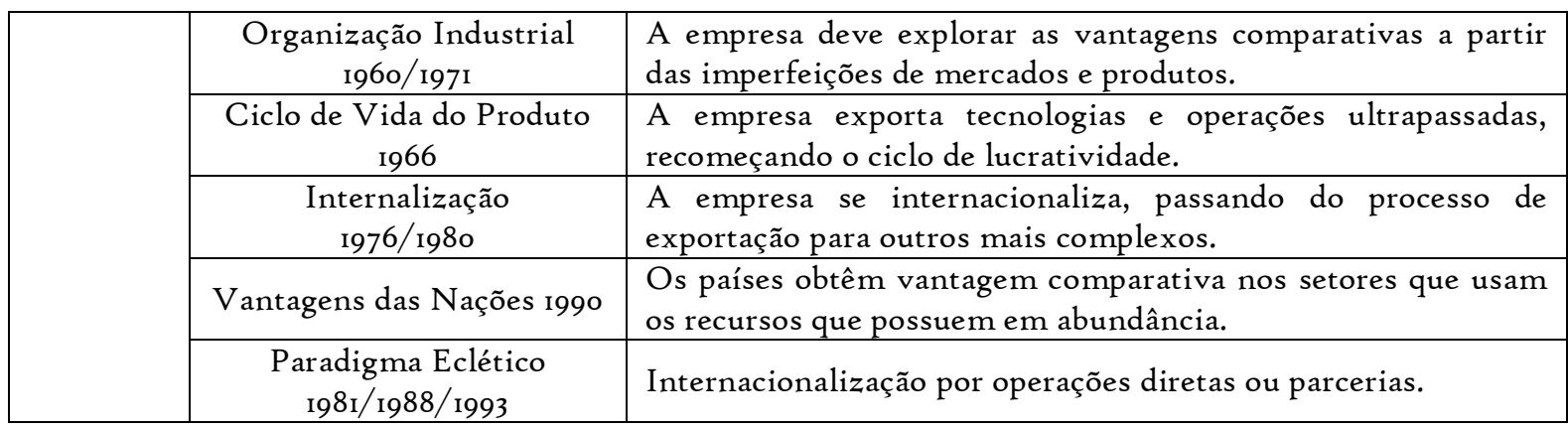

Fonte: Adaptado do artigo O prisma da Internacionalização de Borini et al. (2004).

Para Borini et al. (2004), pelo modelo de Uppsala, as empresas que pretendem se internacionalizar buscam informações sobre o mercado internacional $e$ investem de maneira cautelosa, acompanhando o nível de conhecimento adquirido.

Hilal e Hemais (2003, p. 123) afirmam que o processo de internacionalização está diretamente relacionado a vários campos de estudos devendo ser estudado com profundidade, o que é endossado por Moraes (2005, p. 9), “o modelo traz o conceito de distância psíquica, definida como a soma de fatores que previnem o fluxo de informações de e para o mercado (diferenças em linguagem, educação, práticas de negócios, cultura e desenvolvimento industrial)".

Rodrigues (2006) enfatiza que, tanto para a escola de Uppsala quanto para os seus críticos, a localização é extremamente importante, pois a organização que se internacionaliza e o país escolhido estão interligados por diversos fatores. Para as organizações o ideal é escolher mercados culturalmente (ou psiquicamente) mais próximos, reduzindo riscos implementando investimentos mais "ousados".

Segundo Forsgren (2002, p. 258), o modelo de Uppsala trabalha com conhecimento adquirido. Avalia como as empresas aprendem, e o conhecimento afeta o seu comportamento. Esse modelo contém quatro preceitos que são: o conhecimento do mercado, o compromisso para com o mercado, o compromisso com as decisões tomadas e, por fim, as atividades desenvolvidas pela empresa.

Johanson e Vahlne (1977) apud Forsgren (2002, p. 259) afirmaram que o modelo em questão busca entrar em um determinado mercado, de forma cuidadosa e vagarosa, a fim de minimizar os riscos. Essas empresas procuram interagir com mercados próximos, cuja cultura, linguagem, educação, desenvolvimento industrial e práticas comerciais sejam mais similares às do seu país de origem. Isto é reforçado por Carneiro e Hemais (2003, 
p.13), ao afirmarem que "é razoável aceitar que empresas prefiram menor risco a maior risco e, portanto, prefiram a expansão para países que, supostamente, sejam similares ao seu país de origem".

Considerando os levantamentos primários realizados, a teoria de Uppsala é a que melhor explica o processo de internacionalização, principalmente no universo das MPEs, no qual os recursos são escassos e as decisões devem ser tomadas não impulsivamente, mas, necessariamente, de maneira consciente, ancorada em fatos levantados, ou seja, em experiências adquiridas.

De acordo com Forsgren (2002), o modelo de Uppsala pauta-se na hipótese de que as empresas partem de quatro estágios diferenciados, dependendo do seu grau de internacionalização. São eles: Estágio or: quando não existe nenhuma atividade regular de exportação; 02: quando existe uma atividade regular de exportação, porém essa é realizada por meio de representantes; 03: quando uma empresa abre um escritório de vendas no exterior; 04: quando uma empresa abre uma unidade fabril própria no exterior. Esses estágios descrevem o grau de participação da empresa no mercado internacional. Esse grau baseia-se, principalmente, no conhecimento da empresa em relação ao mercado em que ela pretende se inserir e no compromisso dela perante esse mercado, os quais estão interligados.

\section{CARACTERÍSTICAS DA INTERNACIONALIZAÇÃO}

As empresas que desejam se internacionalizar sempre encontrarão, no percurso, tipos de problemas jamais enfrentados no mercado nacional. No Quadro 2, a seguir, estão descritas as maiores motivações para a internacionalização por parte de MPEs, de acordo com Lorga (2003), adaptado de Czinkota (1999).

Quadro 2- Maiores motivações para a internacionalização por parte das MPEs

\begin{tabular}{|l|lll|}
\hline \multicolumn{1}{|c|}{ Proativas } & \multicolumn{2}{|c|}{ Reativas } \\
\hline$>$ Vantagens em termos de & & \\
lucros & $>$ Pressões da concorrência & \\
$>$ Produtos únicos & $>$ Excesso de capacidade produtiva & \\
$>$ Vantagem tecnológica & $>$ Saturação do mercado doméstico \\
$>$ Informação exclusiva & $>$ Proximidade dos clientes e dos portos de \\
$>$ Compromisso da gestão & & \\
$>$ Benefícios fiscais & & & \\
$>$ Econombarque & & \\
\hline
\end{tabular}


Vieira (2004) defende que o processo de internacionalização de empresas exige uma série de cuidados e procedimentos, que acabam tornando-o uma arte para eliminar barreiras até chegar ao seu objetivo, à perfeição de seu trabalho, com pequena margem de erro e um valor agregado incalculável em sua obra.

Cavalcanti e Alem (2005, p.72) concluem que "a principal motivação para a internacionalização deve ser o aumento da competitividade, essencial para que as firmas possam garantir as parcelas no mercado doméstico já conquistadas”.

Minervini (200I) inclui nas variáveis internas e externas forças competitivas e econômicas, forças políticas e culturais, nível de tecnologia e estrutura de distribuição e geografia. Acrescenta que um esquema básico do Projeto de Exportação deve contemplar sete questões: a avaliação da capacidade exportadora, a identificação e avaliação de oportunidades, a fixação de objetivos, a elaboração da estratégia de internacionalização, a análise dos custos e, por último, mas não menos importante, a revisão periódica dos resultados obtidos. A fixação de objetivos deve responder a questões quantitativas, transformando-se em metas claras, no que tange a volume, prazos, preço, margem de contribuição e Market share pretendidos pela empresa naquele mercado particular.

A análise dos custos deve mostrar as dificuldades em todas as etapas do processo de produção e de comercialização, além de considerar uma eventual necessidade de buscar financiamentos. São relevantes os 04 Ps pregados pelo marketing, ou seja: Preço, Praça, Produto e Promoção, sendo que a praça (seleção de mercado) e produto (adequação do produto) são os Ps que foram mais trabalhados nesta pesquisa. Outros fatores não menos importantes e que também foram levados em consideração, são os canais de comercialização e o grau cultura exportadora existentes ou desenvolvidos pelas MPEs.

É importante selecionar o mercado-alvo para as exportações, como forma de evitar a excessiva diversificação de mercados, clientes e produtos, e a consequente desfocalização de esforços e recursos, definindo-se a estratégia internacional que será utilizada durante o seu processo de internacionalização. Nosé Júnior (2005) afirma que, para se definir uma estratégia, devem ser avaliados os recursos disponíveis nos prováveis cenários e nas ferramentas a serem utilizados, sem se perder de vista o ambiente em que a empresa se encontra inserida. É relevante a proximidade geográfica, tamanho, nível de 
competição existente, perspectiva de crescimento e similaridade cultural. A empresa deve, também, inteirar-se da legislação, do mercado de câmbio, da situação econômica, da concorrência e de outras questões pertinentes ao mercado local, pois apenas experiência interna pode não ser suficiente para a internacionalização da empresa.

DIAS (2002) comenta sobre a importância da pesquisa de mercado, que inclui todos os métodos utilizados para determinação dos mercados externos com maior potencial para colocação de seus produtos. A empresa deve fazer um estudo das ameaças e oportunidades e uma pesquisa quanto à cultura, à economia, aos dados demográficos, ao ambiente de negócios, ao nível de competição, ao nível de tecnologia e à infraestrutura comercial. Deve, também, levantar a legislação do país importador e o calendário local de eventos.

No Gráfico I, encontra-se a Composição das Exportações segundo intensidade tecnológica dos produtos e o tamanho da empresa, mostrando que a maioria das exportações realizadas pelas MPEs brasileiras são de intensidade tecnológica baixa e médio-baixa, e o desenvolvimento da tecnologia precisa ser mais explorado.

Gráfico I - Composição das Exportações segundo a intensidade tecnológica dos produtos, por tamanho da firma - $\mathrm{I}^{\mathrm{o}}$ semestre de 2004 (em \%).

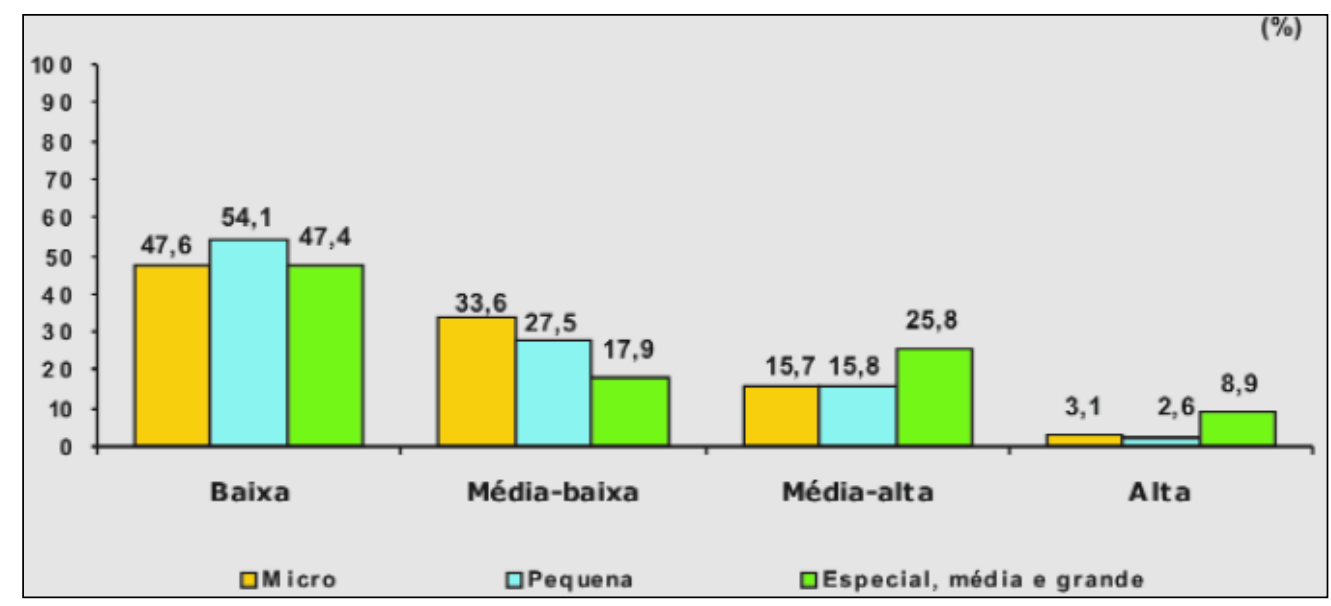

Fonte: SEBRAE (2004)

Conforme comentado por Maia (2006), em decorrência dessa política, as indústrias não ficam em igualdade de condições de serem competitivas para enfrentar o fim do protecionismo, porque os produtos estrangeiros acabam entrando no país em 
melhores condições financeiras e de qualidade, pois eles são ofertados com preços competitivos e de qualidade.

De acordo com Tigre (2002, p.123), "as normas ambientais da série ISO 14000 utilizam procedimentos similares aos definidos para as normas de qualidade que formam um conjunto de atividades a serem realizadas e monitoradas formalmente pelas empresas". No caso das MPEs, investimentos escassos em qualidade e certificação e falta de capacitação do pessoal técnico e do uso de equipamentos de produção e controle de qualidade são fatores que, certamente, contribuem para a formação de uma barreira, quase que intransponível, às suas exportações. Campos (2002) admite falta de profissionalização das empresas brasileiras, quanto a processos de qualidade, fragilizando os setores empresariais nacionais, o que facilita surgimento de novos entrantes (concorrentes).

As necessidades de adaptação tecnológica de produtos e processos variam de acordo com cada setor. $\mathrm{Na}$ indústria de bens e consumos, há necessidade de adaptar a embalagem e seus produtos aos padrões internacionais e, principalmente, aos fatores culturais, políticos e aos hábitos do país consumidor desses produtos.

Campos (2002, p.87) defende que "a padronização torna-se o caminho mais seguro para a produtividade em nível internacional, pois se trata da ferramenta gerencial mais moderna e que deve estar ao acesso dos cargos de chefia, pois se trata de um encargo essencialmente gerencial”. Em âmbito internacional, o design constitui fator mercadológico decisivo, ampliando a competitividade dos produtos e tornando-se essencial para agregar valor e criar identidades visuais para produtos.

Existem vários tipos de comercialização, sendo os principais a Indireta, a Direta, a Mista, o Licenciamento, o Franchising, as Alianças Estratégicas Internacionais e as Joint Ventures. De acordo com Cerceau e Lara (2003), quando se trata de MPEs, os modos de entrada mais usuais são a exportação direta e a exportação indireta. $\mathrm{Na}$ exportação direta, o fabricante do produto é o próprio exportador, enquanto, na exportação indireta, são utilizadas outras empresas para realizar a exportação. Em se tratando de exportação direta, uma das formas mais usuais é a união de várias MPEs, com o objetivo de se fortalecerem e, juntas, enfrentarem o mercado internacional. A essa forma dá-se o nome de consórcio de exportação. Outra forma bastante utilizada pelas MPEs é a inserção direta no mercado 
internacional, mas, de forma gradativa, por meio da participação de missões empresariais, feiras internacionais, projeto comprador, entre outras.

Conforme explícito no site do Ministério do Desenvolvimento Indústria e Comércio Exterior - $\mathrm{MDIC}^{2}$, o termo cultura exportadora está ligado a algumas palavraschave do processo gerencial de uma empresa, que são: competência, eficiência, eficácia, melhoria contínua, qualidade, certificação, compromisso, profissionalismo, capacidade produtiva, padronização, proatividade, dentre outras. essencial assegurar a qualidade nos processos produtivos e no cumprimento dos prazos de entrega deles.

O MDIC desenvolveu ferramentas auxiliares a esses programas para difundir as informações relacionadas ao Comércio Exterior Brasileiro. Algumas destas podem ser encontradas no site mantido pelo Governo Federal chamado Portal do Exportador. Tais como programas de apoio, feiras e eventos, oportunidades comerciais, financiamentos, seguros e crédito, entre elementos primordiais ao processo de internacionalização.

Com os programas Aprendendo a Exportar, Alice web, Radar Comercial, Brazil Trade Net, ENCOMEX, Rede Agentes e outras ferramentas disponibilizadas via web para todos. O governo federal acredita que micro e pequeno empresário já possuem condições de iniciar a implementação da cultura exportadora nas MPEs, sendo os demais passos dados à medida que o conhecimento em relação à importância da cultura exportadora for absorvido. Disseminar a cultura exportadora em uma empresa é tarefa complexa, pois implica aumento de trabalho e a quebra de paradigmas é uma barreira a ser vencida, dependendo também dos funcionários.

\section{CARACTERÍSTICAS DAS MPES BRASILEIRAS}

Segundo o MDIC as micro, pequenas e médias empresas são responsáveis por $80 \%$ da força produtiva do país, ofertando 60\% de toda a empregabilidade brasileira. Juntas, somam $98 \%$ de todas as empresas do setor produtivo. As MPEs e médias empresas respondem por $12 \%$ das exportações, $25 \%$ do PIB e ainda $42 \%$ da massa salarial. O comércio exterior constituiu força de crescimento de países como o México e a China, nos anos I99o, quando (OMC, 200o, citado por Souza, 2005), o comércio cresceu 6\% ao ano, passando de 19\% a 26\% do Produto Interno Bruto - PIB global. A participação brasileira foi de apenas 
0,9\% nesse mercado, índice muito aquém do desejado. Enquanto a participação das empresas brasileiras de pequeno porte, no mercado internacional, responde por menos de 13\% das nossas exportações, em países como Itália, responde por 60\%; nos Estados Unidos, por 54\%; no Japão, por 50\%; na Coréia do Sul, por 48\%; e na Alemanha, por 45\%.

Estudo divulgado pelo SEBRAE, em 2003, estimou que existem cerca de 5,6 milhões de empresas formais, sendo que 99\% são MPEs. Se incluídas as médias empresas, esse segmento é responsável por um quarto do Produto Interno bruto (PIB), 42\% do valor dos salários pagos e 6o\% da oferta de emprego do país.

De acordo com outro estudo realizado pelo SEBRAE no ano de 2005 (SEBRAE, 2006), em 2002, as exportações de bens atingiram US $\$ 60,4$ bilhões, o que representa menos de I\% das exportações mundiais, sendo que apenas 709 empresas, em um universo de 17.407 empresas exportadoras no Brasil realizaram $85 \%$ de todas as exportações brasileiras, montando irrisório, situando o país abaixo de vários países que possuem um grau de desenvolvimento bastante inferior.

Em análise realizada por Markwald e Pessoa (2003), o número de MPEs que exportavam em 1997 era de 9.631, e, no ano de 2002, esse número subiu para 12.676 contabilizando um aumento de, aproximadamente, 30\%. Porém, o valor exportado por essas empresas no total da pauta brasileira caiu de $17,6 \%$ para $13,8 \%$, o que significa que, apesar do crescimento do número de MPEs exportadoras, tem-se registrado uma significativa queda no valor das exportações médias dessas empresas.

Embora as empresas de pequeno porte tenham uma participação pouco significativa no comércio exterior brasileiro, dados estatísticos do SEBRAE (200I), apud Dias (2002), demonstram que elas são um segmento importante, pois atuam em todos os setores produtivos da nossa economia. Cerca de quase 70\% das exportações brasileiras concentram-se nas regiões Sul e Sudeste, tendo como exceção o estado da Bahia, que está entre os estados mais exportadores do país. No ano de 2005, os três maiores estados exportadores foram, respectivamente, São Paulo, Minas Gerais e Rio Grande do Sul.

Diante da teoria apresentada, o que balizará este trabalho trata-se do modelo de internacionalização cuja teoria é proveniente da escola nórdica, além da cultura exportadora. 


\section{METODOLOGIA DA PESQUISA}

O estudo foi desenvolvido na região denominada de Vale do Aço, na cidade de Timóteo-MG, considerada a capital do Inox, produto brasileiro em franca expansão no mercado mundial, sendo Minas o segundo maior estado exportador do país, com crescimento de destaque na pauta de exportações desde a década de 90.

O Estudo de Caso foi possível dado o bom relacionamento entre ambas as empresas e o pesquisador em questão, favorecendo o acesso aos dados e às informações referentes ao processo de internacionalização delas. Ambas as empresas requereram anonimato, para que a concorrência não as identificasse. Por essa razão, a primeira empresa será denominada Alpha, e a segunda, Beta.

Foi adotada a abordagem qualitativa, apropriada para se entender um fenômeno social, estudando suas complexidades, sem a pretensão de numerar ou medir unidades ou categorias homogêneas. Quanto ao tipo, foi realizada pesquisa descritiva, pois foi feito estudo, análise, registro e interpretação de fatos, sem a interferência do pesquisador. A coleta de dados foi feita por meio de um roteiro de entrevista, com os resultados apresentados juntamente à análise documental, realizada em documentos que permitiram a compreensão do histórico e funcionamento duas organizações.

Os dados primários foram obtidos por meio de entrevista semiestruturada, realizada com os gerentes responsáveis pela área estratégica das empresas, e os dados secundários foram obtidos pela análise de documentos internos das empresas. As entrevistas foram realizadas com gestores das MPEs. Investigaram-se as estratégias definidas pelos mesmos e o processo de implementação dessas estratégias. Por último, discutiram-se os resultados alcançados após o processo de internacionalização. A interpretação dos dados consistiu na análise dos documentos e na análise das entrevistas, com base no roteiro proposto.

\section{APRESENTAÇÃO E ANÁLISE DE DADOS}

O primeiro estudo de caso trata da empresa Alpha, cujo processo de internacionalização foi realizado via programas ofertados pelo governo federal. De acordo com um desses programas, um grupo de empresas do mesmo segmento se une para reduzir 
os seus custos e inserir-se no mercado externo. Tal processo recebe o nome de Consórcio de Exportação. $O$ outro programa utilizado pela empresa Alpha é o chamado Projeto Comprador. Por meio dele, o governo federal disponibiliza um subsídio, visando a trazer para o Brasil um comprador em potencial, pré-qualificado pela empresa, cujo interesse comercial é devidamente comprovado por meio documental.

No segundo estudo de caso, a empresa Beta, teve seu processo de internacionalização realizado pelos próprios passos, por meio de estudos e preparação para inserir-se no mercado internacional, de forma profissional e com a implantação de uma cultura exportadora, sempre buscando atingir o objetivo final de tornar-se uma empresa internacionalizada.

\section{Estudo de CAso da empresa AlPha}

Empresa familiar, que, em 20oo, tinha pouco mais de um ano de criação, com quadro de pessoal de três funcionários: o dono da empresa, a esposa e o filho de dezoito anos. Seu faturamento anual era de cerca de $\mathrm{R} \$ 40.000$,oo (quarenta mil reais), o que, em 200o, era suficiente apenas para honrar os compromissos junto aos seus fornecedores, sem que nenhum lucro fosse computado.

A empresa possuía maquinários próprios, financiados pelas instituições financeiras. Além desse fator desfavorável, possuía somente um fornecedor de matériaprima, o que a colocava em uma situação de dependência financeira. Acrescente-se a esse quadro o fato de suas vendas serem esporádicas, uma vez que não mantinha contrato de fornecimento com nenhuma empresa/representante.

Todos os produtos manufaturados pela Alpha eram vendidos em uma feira de artesanato localizada no centro da cidade, onde o dono da empresa possuía uma venda para revender os produtos que ele mesmo produzia. Dentre esses produtos, os mais vendidos eram, em sua maioria, cestas de lixo, caixas de correio, porta lápis, porta-retratos, quadros de aviso e bandejas, todos eles feitos em aço inox.

Além da falta de padrões definidos de produção, não existia controle de produção e custos. A diretoria sabia como produzir o seu produto, porém não possuía conhecimento gerencial sobre o seu negócio. 


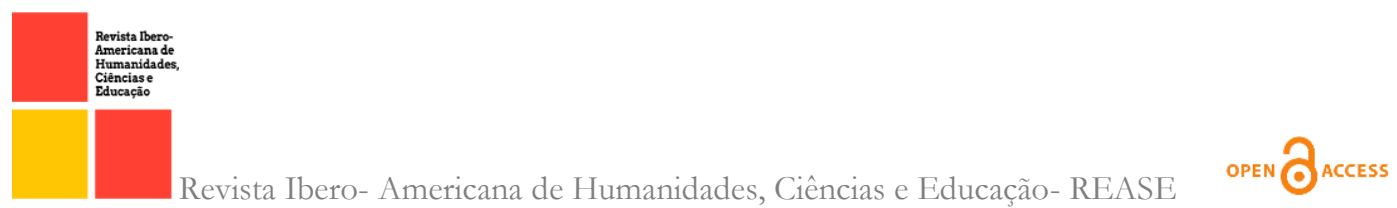

Referentemente à formação profissional, o empresário possuía conhecimento técnico, adquirido no dia a dia de seu trabalho na indústria de segmento similar, localizada naquela cidade, e o filho, universitário, buscava o aprendizado gerencial teórico para que, posteriormente, pudesse aplicá-lo à Alpha.

Esse era o perfil dessa empresa em questão, quando, visando ao desenvolvimento da cidade de Timóteo, lançou, em 1997, um projeto intitulado “Timóteo - A capital do Inox", visando fomentar um polo de inox no município, e difundir, no mercado consumidor brasileiro, a importância daquela cidade, uma vez que ali se instalava a única fábrica integrada de aços planos inoxidáveis e siliciosos da América Latina, responsável, praticamente, por toda a economia da cidade.

Em março de 20oI, a ADT, visando a dar maior destaque ao projeto "Timóteo - A capital do Inox" firmou um termo de Cooperação Técnica para o desenvolvimento de MPEs do setor de artefatos em aço inox dessa cidade juntamente com o SEBRAE. Essa cooperação visava a capacitar e a profissionalizar as MPEs da cidade visando destaque no segmento, tornando-se não apenas uma referência para fortalecer ainda mais o projeto implementado, mas também uma referência na produção e comercialização de seus produtos.

Após serem realizadas várias reuniões entre as entidades acima citadas, decidiu-se que a melhor maneira de projetar a cidade e as MPEs ali existentes era a buscar um apoio do governo federal, por intermédio da Agência de Promoção à Exportação - APEX, que, baseada no programa chamado de Consórcio de Exportação, fomentava o desenvolvimento de MPEs para que essas pudessem atuar no mercado externo, o que chamaria a atenção para a cidade e o seu projeto.

Pode-se dizer que a forma como foi manifestado o interesse em se criar o consórcio de exportação vai contra a teoria defendida por Tomelin (2000, p. 55), que entende que a iniciativa de se formar um grupo deve partir dos próprios empresários da região, ou do setor interessado, e não de instituições ou associações. Para essa autora, "a razão do êxito parte do grupo, de suas ações e iniciativas próprias, por isto o interesse deve surgir dos empresários, até para a facilidade de manutenção da coesão do grupo".

Indo em direção contrária à ideia defendida de que a iniciativa de se constituir um consórcio de exportação deveria partir do empresariado, o SEBRAE, juntamente com a 
ADT, elaborou o projeto para que ele fosse apresentado à APEX. Tal projeto ficou pronto em junho de 200I, quando a ADT anunciou, em Timóteo, que estava recrutando MPEs do segmento de artefatos em aço inox daquela cidade e promoveu uma palestra que tinha por finalidade divulgar o projeto e o seu escopo, além de apontar os resultados esperados.

A palestra, realizada no auditório da ADT, teve a participação de várias empresas do setor, MPEs que eram heterogêneas, pois variavam em relação ao grau de desenvolvimento, à estrutura e à solidez. Após a palestra, onze MPEs decidiram aderir ao programa divulgado pela $\mathrm{ADT}$ e foram incluídas no projeto enviado à $\mathrm{APEX}$.

No momento em que a empresa Alpha decidiu inserir-se no projeto elaborado pela ADT e SEBRAE, segundo a sua diretoria, ela baseou-se na necessidade de ampliação de seu mercado consumidor, uma vez que, em 20or, ela apresentava dificuldades para se promover no mercado, pois a sua única forma de projeção era via feira de artesanato da região.

O microempresário, baseado na sua expectativa quanto à participação da empresa Alpha no projeto proposto, vislumbrou que conseguiria ajuda financeira do governo federal, sem que lhe fossem cobrados juros ou até mesmo o pagamento do valor investido. Ao contrário do que imaginava, durante a palestra ministrada no auditório da ADT, foi informado de que o apoio financeiro do governo não cobriria o valor total do projeto, pois a parte subsidiada pela APEX seria de cinquenta por cento, sendo que o restante caberia aos consorciados, como era praxe nesse tipo de projeto. A empresa Acesita patrocinaria parte desse projeto e seria responsável por setenta por cento da contrapartida, enquanto os consorciados seriam responsáveis por trinta por cento da contrapartida exigida pelo projeto. Tal patrocínio viabilizaria a participação das MPEs da região no projeto referente ao consórcio de exportação, pois suas participações fortaleceriam o projeto já em andamento desde 1997, que visava a firmar a cidade como a capital do inox.

$\mathrm{Na}$ primeira análise da gerência do consórcio de exportação, em agosto de 2002, realizada após uma visita detalhada em cada uma das MPEs envolvidas no consórcio de exportação, concluiu-se que elas eram, de fato, heterogêneas e algumas dessas não possuíam um gerenciamento adequado. Contudo, outras se encontravam bem-organizadas e preparadas para participarem do consórcio. No caso da Alpha, constatou-se que ela não 
estava preparada para se internacionalizar, precisava adequar-se, gerencialmente, à nova realidade.

Considerando que a primeira e a segunda etapas já deveriam ter sido vencidas, o gerente do consórcio passou a cuidar da comercialização dos produtos do grupo. Diferentemente do que esperava, notou haver uma grande disparidade financeira entre as empresas consorciadas. Tomou, portanto, a atitude de contratar uma empresa de consultoria financeira para levantar a real situação de cada uma das consorciadas, e sugerir as devidas providências, visando minimizar a heterogeneidade entre as MPEs.

O relatório final da consultoria revelou que a maioria das empresas congregadas não possuía condição de participarem do consórcio de exportação. Algumas não possuíam condições de estarem funcionando, por isso duas delas foram cortadas do projeto e acabaram encerrando as suas atividades em razão de seu grau de endividamento.

Após a entrega do relatório com o status de cada uma das empresas participantes do consórcio de exportação, foi realizado um curso de empreendedorismo e gestão, baseado nos moldes do projeto Empresa Simulada, um laboratório integrante do sistema de ensino SEBRAE, em parceria com uma instituição de ensino da região. Os micro e pequenos empresários puderam desenvolver uma visão gerencial e colocá-la em prática, ainda que, de uma forma virtual, mas com a vantagem de não pôr em risco o seu estabelecimento durante esse processo de aprendizagem.

Além da atividade acima, foi realizado um curso voltado para a área financeira, visando a capacitar os micro e pequenos empresários a realizarem a administração financeira e orçamentária de sua empresa, uma vez que poucos dos empresários envolvidos possuíam esse conhecimento. Esperava-se, assim, minimizar as falhas ocorridas, devido à falta de planejamento vigente desde o início do processo de formação do consórcio.

Durante as reuniões realizadas periodicamente, verificou-se o alto grau de competitividade entre os empresários ali reunidos. Geralmente, os empresários preocupam-se mais com os ganhos que seu concorrente irá obter do que com o sucesso do seu próprio negócio. A fim de dar um embasamento teórico sobre relações de Comércio Exterior, foram ministrados cursos relacionados ao tema em questão, entre eles Recursos Humanos, Negociação, Legislação e Sistemática, para dar noções de como se portar diante do mercado internacional. A gerência do consórcio de exportação concluiu, todavia, que a 
maioria das empresas não se interessava por esse assunto, pois, embora participassem do consórcio de exportação, demonstravam a intenção de se prepararem para o mercado interno, de se tornarem uma empresa competitiva regionalmente e de conseguirem um incentivo financeiro por parte do governo federal e demais parceiros.

Segundo a diretoria da empresa Alpha, naquele momento, a empresa não se sentia preparada para atuar no mercado interno, e, por isso mesmo, não considerava a possibilidade de concorrer no mercado externo, donde se conclui que ela estava entre aquelas que aspiravam apenas a se tornar uma empresa sólida no mercado interno e, principalmente, rentável.

Assim como outras empresas, a Alpha não realizava investimentos relacionados ao design de seus produtos e, conforme dito anteriormente, tampouco detinha o controle de sua área de produção. Por essa razão, solicitou à gerência do consórcio de exportação que fossem realizados cursos que a auxiliassem na área de produção, tanto na forma de produzir quanto de desenvolver novos designs, o que foi prontamente corroborado por todas as outras empresas envolvidas.

Em uma iniciativa do consórcio de exportação, ADT e o SEBRAE firmaram uma parceria junto à UEMG - Universidade Estadual de Minas Gerais - que oferece um curso de Design. Tal parceria tinha o nome de "Via Design" e tinha como objetivo elevar a competitividade das MPEs, agregando valor aos seus produtos por meio do design. Esse projeto visava a desenvolver tanto o design do produto, quanto a embalagem e a ergonomia.

Em reunião com os micro e pequenos empresários do consórcio, foi distribuída, para cada uma das empresas, a relação dos produtos que elas produziriam em conjunto ou separadamente. Feito isso, a equipe acompanhou o setup do maquinário e o início de produção de cada um dos itens em cada uma das empresas, garantindo, assim, que os procedimentos seriam seguidos e os produtos seriam padronizados e possuiriam a mesma qualidade. A definição de todos esses processos foi devidamente documentada.

Paralelamente a todos os cursos de capacitação oferecidos às empresas consorciadas, a gerência do consórcio de exportação e a diretoria das MPEs participaram da feira internacional do setor, em São Paulo e em Portugal, sempre buscando observar as novas tendências de mercado, o tipo de produto exposto, além da forma como eles eram apresentados. 
Como as diretorias das MPEs consorciadas encontravam-se capacitadas para gerenciar suas empresas, os produtos estavam sendo produzidos de uma forma sistematizada e o design era de primeira qualidade, partiu-se, então, para a segunda etapa. Aproximadamente trinta dias após a participação do consórcio de exportação na feira internacional em Buenos Aires, foi fechado o primeiro pedido de exportação. Um representante de uma empresa coreana enviou folders para a matriz da loja, em Busan, e os proprietários dessa empresa interessaram-se em conhecer melhor os produtos. Para analisar a qualidade deles, fizeram uma compra de porta-retratos, bandejas e utensílios de cozinha, no valor de US\$1оo,oo.

Um mês após a entrega da primeira exportação para o cliente coreano, ele solicitou mais um lote de produtos, sendo que, dessa vez, a venda realizada totalizou US $\$ 500,00$. Foram solicitados também outros produtos, além daqueles comprados anteriormente, porém em uma quantidade maior, pois os importadores estavam comparando se o lote do produto comprado anteriormente estava padronizado com o novo lote.

Foram realizadas mais três vendas para o mesmo cliente, que aumentava gradativamente a quantidade e o valor exportado, sendo que, na última compra, foi solicitado um total de US\$50.00o,oo. A empresa Alpha, todavia, não cumpriu o prazo solicitado pelo cliente, pois, embora tivesse assumido o compromisso de entregar o produto em uma data específica, a mesma priorizou uma grande venda individual no mercado interno, não solicitou prorrogação no prazo de entrega do cliente internacional e não negociou um adiamento na data de entrega para o cliente nacional. Essa empresa simplesmente atrasou a data de entrega do material e não informou esse fato para os demais consorciados. Quando questionada, alegou que a sua prioridade era o mercado interno.

Por não cumprir o acordo pré-estabelecido, o cliente perdeu a confiança nas atividades do consórcio de exportação e não efetuou novas compras, o que criou um clima negativo entre as empresas consorciadas, que acabaram por excluir a empresa Alpha do consórcio de exportação, baseando-se em uma cláusula do seu estatuto que previa punição para a empresa que agisse daquela forma. A partir desse episódio, as empresas começaram a desconfiar uma das outras e não quiseram mais participar do consórcio de exportação, 
passando a agir individualmente. A união proposta, no ato da criação do consórcio de exportação, foi desmantelada. Visando a diminuir o impacto causado pelo insucesso do consórcio de exportação criado, a ADT vislumbrou a criação de um Showroom, onde as micro e pequenas empresas da região poderiam expor os produtos para o mercado. Diante do impasse criado, para atrair o público nacional e internacional, decidiu-se aderir a um outro programa de apoio governamental, o Projeto Comprador.

Extinto o consórcio de exportação, a empresa Alpha voltou a dedicar-se somente ao mercado interno, uma vez que a sua ambição era conseguir ter lucros com o seu negócio e fechar um acordo de fornecimento de longo prazo junto a clientes. Notadamente, o seu objetivo não era alcançar o mercado internacional.

A empresa Alpha profissionalizou-se em determinadas áreas, aumentou o seu faturamento anual para, aproximadamente, $\mathrm{R} \$ 95.000,00$ (noventa e cinco mil reais), passou a contar com seis funcionários em seu quadro e a realizar sistematicamente os controles de processos, de produção e de gerência.

A empresa Alpha não investe mais em design, prefere continuar com os produtos que atualmente produz, e, no futuro, provavelmente, irá copiar as inovações propostas pela concorrência. No momento, não manifesta interesse em internacionalizar-se. Continua comercializando na feira de artesanato, mas conseguiu fechar um contrato de fornecimento junto a uma rede de supermercados da região, que compra, aproximadamente, $75 \%$ de seus produtos fabricados.

\section{ESTUDO DE CASO DA EMPRESA BETA}

A empresa Beta iniciou suas atividades em 1997. Em meados do ano de 1999, a empresa desenvolveu um planejamento estratégico, visando a profissionalizar-se e a tornar-se referência no segmento de artefatos em aço inox no mercado nacional. Com essa iniciativa, a gerência buscava inserir-se no mercado internacional. Com o planejamento estratégico, a empresa pôde realizar uma análise swot ${ }^{3}$ e identificar quais eram as ameaças e oportunidades, além das suas forças e fraquezas, para se adequar à nova realidade que ela buscava implantar. 


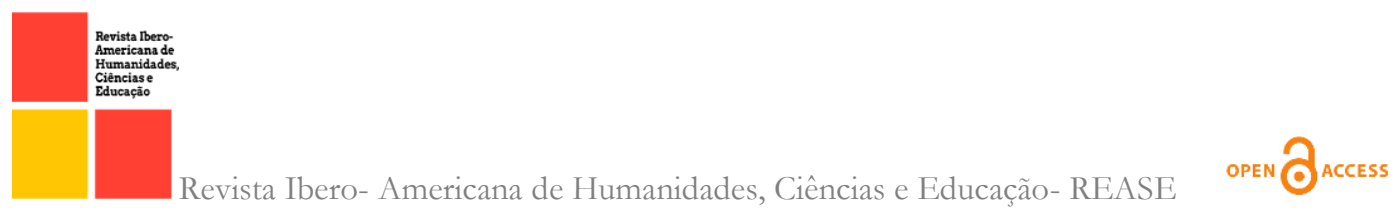

Em 1999, a empresa contava com um quadro de cinco funcionários, e cada um deles estava locado em áreas já pré-estabelecidas pela diretoria: área comercial, financeira e industrial. O faturamento anual da empresa girava em torno de $\mathrm{R} \$ 240.000,00$ (duzentos e quarenta mil reais).

Ao desenvolver o planejamento estratégico, realizado juntamente com uma empresa de consultoria contratada na época, a empresa Beta optou por trabalhar a nobreza do aço inox e a criatividade como insumos básicos da Empresa, com o objetivo de abastecer o mercado de decoração e utensílios domésticos com artigos de qualidade, porém, a custo baixo.

Definiu-se, então, que se deveria investir em algumas áreas e criaram-se quatro departamentos distintos: departamento de desenvolvimento de produtos, de marketing, de qualidade e de desenvolvimento humano. Foram contratados quatro novos funcionários qualificados para atuar nas áreas criadas. Para manter essa estrutura, que geraria alto custo, a empresa optou por buscar um sócio que fosse, necessariamente, empreendedor, e que vislumbrasse esse novo cenário definido. Além do mais, ele deveria ter condições de fortalecer financeiramente a empresa.

Estabelecida a sociedade, a Beta procurou adaptar-se a sua nova realidade. Iniciou-se, então, uma maciça participação da empresa em feiras nacionais e internacionais no setor, inicialmente como visitante, para inteirar-se do que o mercado ofertava, e atender, de forma mais segura, os anseios do mercado consumidor. Paralelamente à participação em feiras nacionais e internacionais, a área de marketing procurou analisar, junto aos sistemas informatizados de comércio exterior disponíveis no mercado, a situação atual dos produtos oferecidos. Primeiramente, a empresa passou a manipular os dados disponíveis pelo sistema Alice, responsável pela análise de informações de Comércio Exterior, que buscava, do sistema SISCOMEX, todas as informações referentes às exportações realizadas pelo Brasil. Trata-se de um sistema atualizado mensalmente, cujas informações são alimentadas pelo SECEX, órgão do governo federal.

No sistema ALICE, estão disponíveis, para consulta, as informações relacionadas ao tipo de mercadoria exportada, ao país importador, ao bloco econômico importador, à unidade da federação exportadora, à via de transporte utilizada para exportar e ao porto utilizado para escoar a mercadoria. 
A área de Marketing buscou, ainda, informações em outros sistemas como, por exemplo, o Radar Comercial, também desenvolvido pelo SECEX. Trata-se de um instrumento de consulta e análise de dados relativos ao comércio exterior, cujo principal objetivo é auxiliar na seleção de mercados e produtos que apresentam maior potencialidade para o incremento das exportações brasileiras. Os dados e análises disponíveis nesse sistema são relatados por triênio, a fim de demonstrar as tendências mercadológicas e evitar sazonalidades.

Outra ferramenta bastante utilizada pela área de Marketing da Beta foi o BrazilTradeNet, um portal de promoção comercial do Ministério de Relações exteriores MRE - que é a maior e mais completa rede de informações comerciais da América Latina, criada para estimular as exportações brasileiras. Esse sistema fornece as demandas pelos produtos brasileiros e ainda disponibiliza publicações do gênero, além de pesquisas de mercado internacionais e informações sobre eventos.

Pesquisou-se, também, o TradeMap, outro sistema que fornece dados estatísticos de comércio exterior para o desenvolvimento de negócios internacionais e apresenta indicadores de desempenho de exportação, demanda internacional e mercados alternativos. Permite, ainda, análise do papel da concorrência, seja do ponto de vista de determinado produto, seja de um país. O TradeMap foi desenvolvido pela Seção de Análise de Mercados do International Trade Centre e oferece acesso on-line à maior base de dados sobre comércio exterior do mundo.

A Beta passou a participar de eventos de comércio exterior promovidos por várias entidades relacionadas ao tema, como, por exemplo, o MDIC, FIEMG, Câmaras de Comércio etc. Paulatinamente, a empresa foi adquirindo conhecimento técnico sobre o mercado internacional.

Após analisar as diversas informações obtidas pelos sistemas anteriormente citados, a área de marketing chegou à conclusão de que a melhor forma de se inserir no mercado internacional seria buscando parceiros em mercados próximos ao brasileiro, optando, assim, primeiramente, por mercados situados na América do Sul. Um dos países que demonstrou grande receptividade aos produtos comercializados pela Beta foi o Chile, dada a sua intenção de estabelecer uma relação comercial de artefatos em aço inox. 


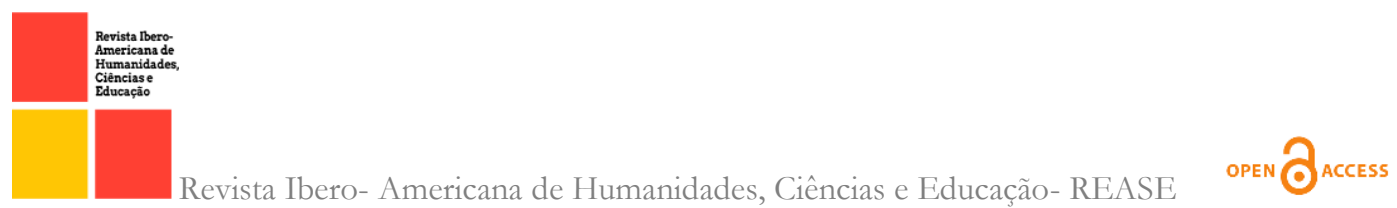

Buscou-se, portanto, adequar os produtos produzidos pela Beta às exigências do mercado chileno. Juntamente com a área desenvolvimento, a área de marketing começou a projetar novos produtos e embalagens mais adequadas, além de definir processos e procedimentos que respeitassem a legislação e a cultura chilenas.

Por intermédio do sistema BrazilTradeNet, apresentou-se uma oportunidade de negócios com o Chile, por intermédio de um importador interessado em revender produtos relacionados a artefatos em aço inox. Firmou-se um contrato de um ano, segundo o qual o importador passava a agir, no Chile, como agente exclusivo da empresa Beta. Fechou-se, portanto, uma primeira exportação para o Chile, que totalizou US $\$ 3.500,00$, e a venda, segundo informações passadas pelo agente chileno, foi um sucesso. A segunda foi de aproximadamente US $\$ 10.000,00$; a terceira de $U S_{\$ 20.000,00}$ e a quarta girou em torno de US\$40.0oo,oo.

A empresa Beta empenhava-se cada vez mais em atender seus clientes com um padrão de qualidade elevado. Em nenhum dos lotes exportados para o Chile detectou-se qualquer avaria, ou itens de qualidade duvidosa, o que gerou uma relação de confiança entre o importador e o exportador.

A cadeia de lojas especializadas em utensílios domésticos fechou um contrato de exportação com a Beta com a duração de um ano. Foram programadas entregas mensais cujo valor das mercadorias exportadas chegava a, aproximadamente, US $\$ 20.000,00$.

Com o sucesso alcançado junto a esse fornecedor, o agente chileno tem tido condições de fechar mais alguns negócios, e as vendas vêm crescendo sistematicamente, partindo dos US $\$ 9.000,00$ (mensais), alcançando US $\$ 22.000,00$ (mensais) em pouco mais de três anos de atividade exportadora naquele país.

Uma atitude por parte da empresa Beta que ajudou a alavancar as exportações de seus produtos para aquele país foi a sua proatividade. Vislumbrando ser reconhecida pela qualidade de seus produtos, a empresa investiu em certificações de qualidade, como, por exemplo, a ISO goor que, é uma forma útil para que uma organização seja capaz de demonstrar que ela gerencia seu negócio e, desta forma, alcança uma qualidade consistente.

Atualmente, existem empresas chilenas interessadas em negociar com a Beta; porém, ela firma novos negócios se puder garantir a qualidade de seus produtos e a data de 
entrega compromissada. Diante de sua limitação produtiva, a mesma só tem condições de fechar novas vendas para o início do ano de 2008.

Neste ano de 2007, a empresa Beta, vislumbrando o aumento de sua capacidade produtiva, iniciou estudos para se inserir no mercado argentino, contando com a proximidade geográfica e similaridade com essa cultura, e projeta um crescimento de I00\% (cem por cento) de suas exportações para os próximos três anos. A diretoria da Beta admite competir, em termos de qualidade de seus produtos, com grande força do mercado em questão, que é a marca Tramontina.

A Beta pretende firmar-se de forma mais ampla no Brasil. Abriu loja própria na cidade de Belo Horizonte, onde demonstra e comercializa os seus produtos habituais, objetos de decoração, materiais de escritório, linha banheiro e linha culinária, e passou a produzir luminárias, móveis em alumínio, produtos que, segundo a diretoria da empresa, estão sendo bem aceitos tanto no mercado interno, como no mercado internacional. Aumentou o seu faturamento anual para, aproximadamente, $\mathrm{R} \$ 890.000,00$ (oitocentos e noventa mil reais), 80\% provenientes de Exportações. Dezoito funcionários qualificados realizam constantes treinamentos, definidos pela área de desenvolvimento humano da 268 empresa.

A empresa Beta encontra-se composta por nove áreas distintas, investe significativamente em design, qualificação e aperfeiçoamento de funcionários, inovando para ficar à frente da concorrência. Expõe seus produtos em feiras nacionais e internacionais e pretende inserir-se nos demais mercados pertencentes ao MERCOSUL. Outra intenção é abrir uma loja ou centro de distribuição no Chile, para melhorar o controle em sua logística, o atendimento aos clientes e diminuir custos e prazos de entrega.

\section{CONSIDERAÇÕES FINAIS}

A análise do processo de internacionalização de duas micro e pequenas empresas localizadas na região do Vale do Aço em Minas Gerais permitiu conhecer que, em princípio, nenhuma das duas empresas possuía conhecimento sobre os modelos de internacionalização existentes. 


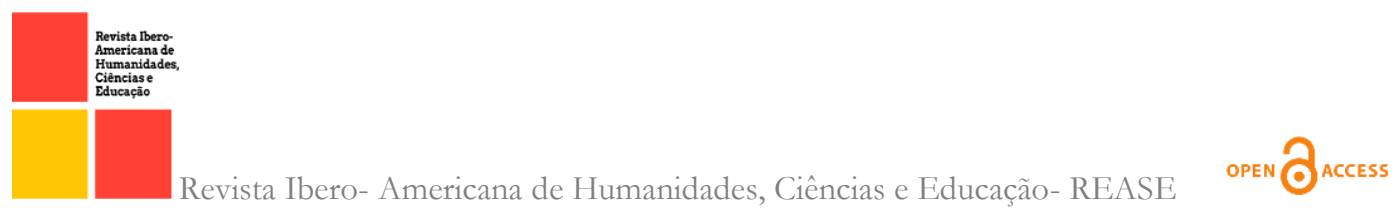

Embora a empresa Alpha conseguisse grande apoio do governo e de entidades de classe, sendo incluída em um consórcio de exportação, por pretensão de organizações políticas da região, não buscou conhecimento, cresceu limitado.

Já a segunda empresa analisada optou por se internacionalizar para crescer, visando à oportunidade de explorar novos mercados com segurança, contratando pessoas competentes, capazes de adequarem-se à nova realidade definida por meio de um planejamento estratégico.

Após análise do processo de internacionalização adotado, é possível reconhecer que ambas cresceram. Os faturamentos da Alpha aumentaram aproximadamente 100\%, já o crescimento adquirido pela Beta foi de aproximadamente de $370 \%$, no curto prazo de pouco mais de dois anos.

Ambas as empresas não possuíam certificações de qualidade, mas a Beta desenvolveu esse interesse e trabalhou para ter condições de adquiri-las. A empresa Beta buscou certificação de qualidade para o fortalecimento de sua marca no mercado internacional e até mesmo no mercado nacional, baseando-se no modelo de Uppsala. Já a empresa Alpha A Alpha somente admitiu que deveria adotar procedimentos padrões; porém, não julgava necessária a aquisição de certificação de qualidade, por não vislumbrar a sua projeção no mercado internacional. Só conheceu o consórcio de exportação quando convidada para participar dele.

Enquanto a empresa Alpha utilizou-se, logo no início, do fomento do governo federal, a empresa Beta não tinha conhecimento desse apoio, buscando informar-se sobre suas vantagens e desvantagens no decorrer do planejamento estratégico e decidiu que tal apoio seria utilizado em um segundo momento.

Ambas as empresas conheciam variados projetos ofertados pelo governo federal, pois participaram de congressos, seminários e cursos que explicavam de que forma os órgãos governamentais podem contribuir com aquelas empresas que desejam exportar seus produtos.

Quanto à direção da empresa Alpha, ela inseriu-se no projeto de internacionalização, sem ter realizado esse estudo, e tal análise iniciou-se a partir do incentivo da gerência do consórcio de exportação. 


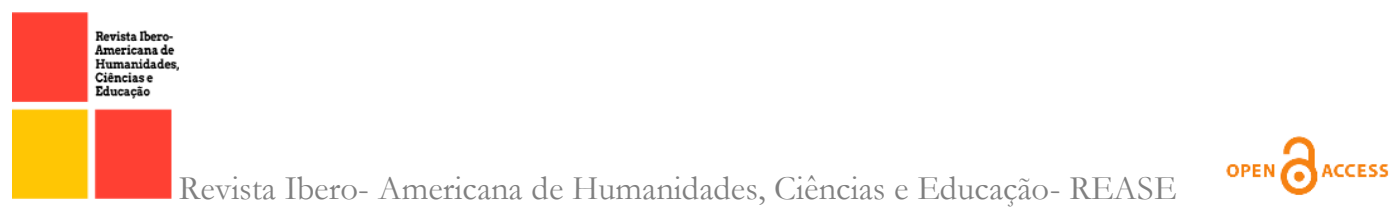

Objetivando adaptar-se à realidade, a diretoria da Beta revisa, anualmente, seu planejamento estratégico, feito desde o início de suas atividades. Trata-se de uma medida muito importante e eficaz, uma vez que os mercados nacional e mundial encontram-se em constante transformação, e essa é uma forma de se manter atualizado com as novas tendências do mercado.

As duas diretorias descobriram a importância do design de seus produtos e embalagens, que, bem desenvolvidos atraem a atenção do mercado consumidor e demonstra ser um produto de qualidade de sofisticada.

Apesar de a diretoria da empresa Alpha ter tido a oportunidade de medir os ganhos desse item, ela decidiu, por razões financeiras, não o explorar mais, preferindo copiar produtos do concorrente, bem aceitos no mercado.

Para a empresa Beta, o sucesso nacional e internacional de seus produtos decorre do investimento que no design de produto e embalagens, sempre atendendo às necessidades específicas do cliente, detectadas por pesquisa de mercado.

Internacionalizar não é tarefa fácil, demanda muito investimento em tempo, dinheiro, capacitação, entre outros. O sucesso na atividade exportadora, permanente ou eventual, será obtido por meio de planejamento estratégico a médio e longo prazo, com relação aos mercados externos.

Mesmo com o apoio ofertado pelo governo federal, algumas empresas não conseguem se internacionalizar de fato. Empresas despreparadas, desinteressadas e cuja cultura não seja condizente à finalidade dos programas de apoio do governo federal podem facilmente prejudicar o sucesso destes.

Este estudo permite sugerir um processo mais criterioso de seleção das empresas a serem apoiadas pelos programas de internacionalização ofertados pelo governo federal, verificando se as empresas candidatas a esses programas estão preparadas para tal ação e se possuem o real interesse de se internacionalizarem.

Deveriam ser aceitas aquelas que tivessem participado de outro programa governamental de desenvolvimento gerencial, e, quando aptas a prosseguirem uma nova etapa, poderiam participar desse tipo de projeto, evitando o gasto de milhões de reais de investimentos com empresas que não buscam a eficiência com método e competência, não 
gerando retorno financeiro para o país, além de prejudicarem faturamento e imagem de suas parceiras.

\section{REFERÊNCIAS}

APEX. Critérios e Parâmetros para os instrumentos de promoção comercial apoiados pela APEX Brasil. Disponível em <www.apexbrasil.com.br/media/criterios.doc $>$. Acessado em 24 de junho de 2021.

BORINI, Felipe, COELHO, Fernanda, RIBEIRO, Fernanda, PROENÇA, Eduardo. O prisma da Internacionalização IN Seminário de Administração - VII SEMEAD, 2004.

CAMPOS, Vicente. Qualidade Total: Padronização de Empresas. Belo Horizonte: Fundação Christiano Ottoni, 2002.

CARNEIRO, Jorge, HEMAIS, Carlos. Internacionalização de Serviços: Relativização das Generalizações do Modelo de Uppsala. São Paulo: 2003.

CAVALCANTI, C. E., ALEM, A.C. O BNDES e o apoio à internacionalização das empresas brasileiras: Algumas reflexões. Rio de Janeiro, 2005. Revista do BNDES, v. 12, n. 24, dez. 2005: 43-76.

CERCEAU, J., LARA, J. E.. Estratégias de internacionalização de empresas: Uma abordagem Teórica. Mimeo, 2003.

DIAS Adilson. Reflexões e ações para a internacionalização da pequena empresa brasileira. Florianópolis, 2002. Dissertação de Mestrado, UFSC, 2002.

FORSGREN, M. The concept of learning in the Uppsala internationalization process model: a critical review. International Business Review, vol. II, p.257-277, 2002.

HILAL, Adriana, HEMAIS, C. A. O Processo de internacionalização da firma segundo a escola nórdica. São Paulo. RAC, v.7, n.I, Jan/Mar. 2003:109-I24.

KUAZAQUI, Edmir. Marketing Internacional: Como conquistar Negócios em Mercados Internacionais. São Paulo: Pearson Education do Brasil, 1999. 
LORGA, S.C. e S. Internacionalização e redes de empresas: conceitos e teorias. Lisboa: Verbo, 2003.

MAIA, J. Economia internacional e comércio exterior. São Paulo: Atlas, 2006.

MARKWALD, Ricardo \& PESSOA, Elisa. Micros e pequenas empresas exportadoras no Brasil: um retrato. In: FUNCEX. Revista Brasileira de Comércio Exterior. Edição nº. 76, 2003.

MINERVINI, Nicola. Exportar: competitividade e internacionalização. São Paulo: Makron Books, 200I.

MDIC - Ministério do Desenvolvimento, Indústria e Comércio Exterior. Disponível em $\langle$ www.mdic.gov.br $\rangle$. Acessado em o5 de novembro de 2021.

MORAES, Walter F. A.. Modos de entrada e teoria de internacionalização: uma análise crítica. São Paulo: Cladea, 2005.

NOSÉ JÚNIOR, Amadeu. Marketing internacional: Uma estratégia Empresarial. São Paulo: Pioneira Thomson Learning, 2005.

RODRIGUES, F. Repensando a localização e a vantagem competitiva nos negócios internacionais. IX SemeAd. USP, agosto de 2006.

SEBRAE - Núcleo de Promoção de Negócios Internacionais. Disponível em <www.sebraenet.com.br/sini $>$. Acesso em 02 de agosto de 202I.

SEBRAE - $\quad$ Observatório SEBRAE. Disponível em <www.sebrae.com.br/br/pesquisa_exportacaor/index.asp〉. Acesso em 27 de outubro de 202I.

SOUSA, Tomás, PALACIOS, José. Estratégias de marketing internacional. São Paulo: Atlas, 2004. 
SOUZA, Rodrigo. Internacionalização de micro e pequenas empresas: Uma visão Gerencial. Ipatinga, 2005. Monografia (Pós-graduação em Marketing), Universidade Candido Mendes.

TIGRE, P. B. Papel da política tecnológica na promoção de exportações. IE/UFRJ. 2002.

TOMELIN, Letícia. A formação de consórcio de exportação em Santa Catarina. Florianópolis, 200o. Dissertação (Mestrado em Engenharia de Produção) - Programa de Pós-graduação em Engenharia de Produção, UFSC, 2000.

VIEIRA, Hercílio. Procedimentos para internacionalização de micro e pequenas empresas. Florianópolis, 2004. Dissertação (Mestrado em Engenharia da Produção) - Programa de Pós-graduação em Engenharia da Produção, UFSC, 2004. 